\section{Crises capitalistas, engodos tecnocráticos e democracia transnacional}

HABERMAS, Jürgen. Na esteira da tecnocracia: pequenos escritos politicos XII. Trad. Luiz Repa. São Paulo, Editora da Unesp, 2014. 261 pp.

\section{Ivan Rodrigues}

Doutorando pelo Programa de Pós-graduação em

Filosofia da Universidade Federal de Santa Catarina

(UFSC), com pesquisa amparada por bolsa da Coordenaçáo de Aperfeiçoamento de Pessoal de Nível Superior (Capes). E-mail: <ivanrsfilho@hotmail.com>.

DOI: $10.17666 / 339618 / 2018$

\section{1}

Em A Europa evanescente de Jürgen Habermas, resenha da tradução estadunidense de $\mathrm{Na}$ esteira da tecnocracia (NET), Jeremy Waldron (2015) realiza uma recepção de $N E T$ do ponto de vista da integração política europeia. O filósofo neozelandês apresenta essa obra como "o quarto livro de Habermas sobre a Europa", cuja "principal preocupação" seria "o futuro da democracia na Europa". Ele não deixa de registrar implicaçóes de $N E T$ que vão além da União Europeia, mas esse registro é lateral a seu enfoque sobre os deficits democráticos europeus.

Aqui pretendo realizar uma recepção da tradução brasileira de $N E T$ (da lavra de Luiz Repa) que se dissocia do ponto de vista de Waldron e adota o ponto de vista de uma democracia transnacional. Trata-se, pois, de uma recepção centrada na idealização realista e crítica de uma democracia que:

1. ancora-se nos Estados nacionais;

2. abrange arranjos supraestatais (como a União Europeia) destinados a uma persecução justa e solidária de metas pragmáticas comuns de Estados nacionais;

3. avança para um parlamento mundial e uma constituição global a fim de domesticar o poder social que, escapando aos Estados nacionais e às alianças regionais entre eles, cada vez mais forja decisóes que afetam agudamente os cidadãos mundiais, mas não são deliberativamente filtradas por eles por não haver canais institucionais para tanto.

A recepção aqui realizada, portanto, não é eurocêntrica, mas universalista: refere-se à democratização não meramente da união monetária europeia, mas, antes, da subpolítica transnacional.

2

Antes de frisar a idealização de uma democracia transnacional como o cerne normativo de NET e a chave para sua compreensáo, gostaria de expor os traços principais do texto.

A edição brasileira é aberta por uma apresentação de Sérgio Costa ("Jürgen Habermas, o intelectual público"), que destaca que, em NET, Habermas compila recentíssimas intervenções suas como "intelectual público": como acadêmico que participa em esferas públicas politizadas para retirar do banho-maria da política usual questóes políticas centrais, propondo argumentos radicalmente democráticos que aqueçam a deliberação coletiva. Habermas ratifica Costa ao destacar, no prefácio, que a obra se baseia em uma "separação de papéis a separação entre 'intervenções' de um intelectual e o trabalho científico do professor” (pp. 25-26).

Costa também destaca que, se o texto é do intelectual público Habermas, o acadêmico Habermas não está ausente nele. Ao contrário, o acadêmico municia teoricamente o intelectual público, e o intelectual público traduz politicamente o acadêmico. Habermas, de novo, ratifica Costa ao assinalar que "as profissôes científicas não aceitam aquela separação de papéis” (p. 26). Assim, NET é tanto mais prenhe de sentidos, conceitos, argumentos e teses quanto mais é lida em reconexão com as teorias habermasianas da sociedade, do direito e da democracia. Por isso, vários conteúdos abreviados de NET são passíveis de desenvolvimento teórico posterior.

É necessário, entretanto, observar que cinco entre os catorze capítulos que formam a compilação (os capítulos 1, 2, 4, 5 e 9) possuem eminente 
caráter acadêmico. Isso é tanto menos negligenciável quanto mais se considera que os capítulos 4, 5 e 9 são o coração da obra. O capítulo 5, aliás, carrega o mesmo título da compilação. Julgo que os capítulos 4, 5 e 9 são os capítulos principais porque: 1 ) são os que mais direta e sistematicamente se ligam à idealização de uma democracia transnacional; 2) essa idealização torna NET relevante para leitores não alemães e não europeus, despe-a de etnocentrismo, eleva-a para além de seus contextos de interesse imediato e reveste-a de interesse universal; 3) uma leitura de $N E T$ que perde de vista aquela idealização é uma leitura empobrecida porque fracassa em refazer a conexão da obra com seu pano de fundo teórico, no qual a democracia transnacional aparece como o alargamento e o aprofundamento da autonomia pública dos cidadãos mundiais.

Por fim, cabe observar que a obra contém quatro seçôes. A seção I toca em uma ferida política alemã, a saber, o ensimesmamento nacionalista e seu ápice nazista, injetando nela uma prestação de contas intelectual (capítulo 1), uma filosofia do diálogo (capítulo 2) e uma fonte literária pós-nacional (capítulo 3). As seçóes II e III reconduzem o leitor da problemática da autocompreensão política contemporânea dos alemães até a antecipação temática que ele (o leitor) realizou ao deitar os olhos sobre o título do livro e que tem a ver com as ameaças tecnocráticas à soberania popular: ocorre que o poder tecnocrático que Habermas denuncia trafega não só sobre trilhos nacionais, mas também em linhas transnacionais. E a seção IV reúne pequenos escritos elaborados por ocasião de homenagens e que levemente suscitam temas políticos transnacionais.

\section{3}

Levantadas essas notas preliminares sobre como ler NET, incumbe realçar brevemente o principal em cada capítulo, destacando-lhes o conteúdo democrático-transnacional.

Os três primeiros capítulos, que formam a seção I, partilham quatro características: 1) têm como mote o exílio político de intelectuais de proveniência judaica em face do nazismo; 2) partem desse mote para abordar o nacionalismo patológico, que se embriaga de preconceitos éticos moralmente inaceitáveis; 3) têm como cerne filosófico-político o princípio pós-nacional que distingue nação de Estado e desnuda o caráter construído, mutável e carente de justificação de nação e Estado; 4) frisam o papel de intelectuais (filósofos, cientistas sociais, artistas) na denúncia moral do nacionalismo patológico e na elaboração pública do princípio pós-nacional.

O capítulo 1 ("Filósofos e sociólogos judeus como regressados à antiga Alemanha Ocidental. Uma recordação") faz o reconhecimento do papel intelectual desempenhado por acadêmicos de origem judaica na reconstrução sociológica e filosófica da Alemanha Ocidental submersa nos destroços da Segunda Guerra Mundial: "Os emigrantes judeus tornaram-se professores insubstituíveis para uma geração mais jovem após o retorno à pátria que os expulsara” (p. 33). O papel intelectual que Habermas atribui aos regressados corresponde à tarefa de analisar e criticar as tradiçóes alemãs moralmente distorcidas, tarefa que eles levaram a cabo com a agudeza de quem estivera sujeito à eliminação racial. O capítulo destaca a contribuição ética (como análise crítica) dos professores de ascensão judaica que, apesar da malignidade moral nazista, retornaram às universidades alemãs (ou, permanecendo no exílio, como Hannah Arendt, impactaram-nas amplamente) e marcaram profundamente a formação teórica e as orientaçôes práticas das jovens geraçôes de estudantes emergentes da destruição bélica, da ruína moral e da perplexidade política: o próprio Habermas foi assim marcado.

Trata-se em última análise de observar que são moralmente infundadas as tradiçóes éticas que minam a atribuição da igualdade moral a grupos racialmente diferentes e, portanto, respaldam o estabelecimento de relaçôes de dominação nas quais os grupos raciais eticamente rebaixados são submetidos ao arbítrio do grupo racial que a si próprio designa infundadamente superioridade moral, ou seja, exclusividade de direitos morais.

O capítulo 2 ("Martin Buber - a filosofia do diálogo no contexto histórico de sua época") destaca "a relação entre Eu e Tu, em torno da qual se cristalizou o pensamento filosófico de Buber” (p. 54). A filosofia da religião de Buber caracteriza-se por conceber 
a relação entre o que ora e Deus como uma relação dialógica na qual "Deus [se faz presente] como uma segunda pessoa" e a qual "é mediada por palavras e pela 'palavra"' (p. 55). A relação interpessoal e linguística entre o que ora e Deus (Tu eterno) é o a priori de todas as relaçóes intramundanas entre seres humanos, as quais se distinguem das relaçóes sujeito-objeto: as primeiras (relações Eu-Tu) requerem “o entrelaçamento recíproco das perspectivas que os participantes dirigem uns aos outros, no que cada um pode adotar a perspectiva do respectivo outro" (p. 56); as últimas (relações Eu-Algo) são assimétricas porque o objeto é incapaz de oferecer uma resposta à pessoa que o observa. Nas relaçóes Eu-Tu, "os participantes não se espionam ou se espreitam mutuamente como objetos, mas se abrem uns aos outros" (p. 57). Não obstante, as pessoas "podem blindar-se e tratar o respectivo outro não na segunda pessoa, mas como um objeto, da perspectiva de uma terceira pessoa - seja instrumentalmente, como o médico que opera o corpo de um paciente, seja estrategicamente, como o colega do banco que impinge um crédito a seu cliente ludibriado" (p. 58). Portanto, as relaçóes entre pessoas podem ser afetadas pela objetivação do outro. Habermas destaca como a tese básica da filosofia do diálogo de Buber a intuição de que: "O que é constitutivo do espírito humano é o entrelaçamento da relaçáo intersubjetiva entre destinatário e falante, de um lado, e as relaçóes intencionais respectivas com alguma coisa no mundo objetivo, sobre a qual os dois se entendem, de outro lado" (p. 65).

Nesse capítulo, destaca-se uma orientação fundamental à democratização transnacional: segundo Buber, "não existe um nexo necessário ou mesmo normativamente fundamentado entre a nação crescida naturalmente ou fundida e o Estado deliberadamente construído por seus cidadãos" (p. 70), de modo que o Estado não se reduz à promoção institucional de uma nação. Antes, "a justificação de todas as formas de convívio se mede, para ele, em última instância, pelas tomadas de posição autênticas de seus membros" (p. 71). Assim, o Estado só se justifica se estabelece garantias institucionais de que o convívio entre coletividades nacionais diversas, tanto dentro como fora das fronteiras estatais, seja orientado pela inclusão dialógica e pela aber- tura racional, mas não pela exclusão monológica e pelo autofechamento arbitrário.

O capítulo 3 ("Heine contemporâneo: 'Agora não há mais nenhuma nação na Europa”") ressalta que, em sua produção literária, o romântico esclarecido Heinrich Heine "sempre distinguiu cuidadosamente os 'preconceitos nacionais' do 'amor à pátria” e, por conseguinte, "admira o patriotismo francês e inveja os franceses, que podem pintar o amor pela pátria com cores cosmopolitas” (p. 74). Habermas, assim, apresenta eloquentemente Heine como "o escritor que dera à questão 'Qual é a grande tarefa de nosso tempo?', no ano de 1828 , uma resposta sem rodeios: 'É a emancipação. Não meramente a dos irlandeses, a dos gregos, a dos judeus de Frankfurt, a dos negros das Índias Ocidentais [...], mas é a emancipaçáo do mundo inteiro"” (p. 76). A emancipação mundial consiste na luta pela "unidade enfática de democracia, direitos humanos, esperança cosmopolita e pacifismo", na qual também está embutida "a emancipação social, a 'grande questão sobre a sopa”" (p. 78). Em última análise, Habermas desvela em Heine a grandeza de ter traduzido literariamente o espírito da época revolucionária, isto é, o núcleo normativo político universalista da modernidade.

Habermas, então, ressalta que, depois do século XX, "vivemos em uma época pós-revolucionária e pós-heroica” (p. 84), na qual os extremos políticos da modernização reduzida à obtenção eficiente de ganhos econômicos são inaceitáveis. No entanto, ele adverte que, mesmo nessa época de resfriamento das medidas revolucionárias e dos atos heroicos, a política democrática não deve curvar-se à economia capitalista.

\section{4}

Os cinco últimos capítulos de NET, que compóem a seção IV, podem ser vistos como comprovação de que, até em suas participações em homenagens, Habermas não perde a ocasião de insistir, ainda que sutilmente, em temas da democratização transnacional.

No capítulo 10 ("Racionalidade de paixão. Ralf Dahrendorf em seu aniversário de 80 anos”), Ha- 
bermas, encarregado de celebrar o sociólogo liberal Dahrendorf, aproveita para sublinhar que nossa época se caracteriza por um espírito pós-heroico, isto é, desguarnecido de belicismo e não assombrado pelo totalitarismo. Porém, isso não significa que nossa época seja despida de utopia e esteja condenada ao quietismo anestesiado e ao conformismo impotente. Ao contrário, nossa época é plena de desafios de democratização transnacional e reclama de nós, cidadãos mundiais, indignação moral, mobilização transformadora e deliberação crítica.

No capítulo 11 ("Perfuraçóes na fonte do espírito objetivo. Prêmio Hegel para Michael Tomasello"), Habermas, quando da entrega do notável Prêmio Hegel (que ele próprio recebera em 1973) ao psicólogo do desenvolvimento Tomasello, registra que o laureado clarificou empiricamente "a questão filosófica sobre o surgimento da constituiçấo social do espírito humano" (p. 217). Tomasello "náo se concentra mais no sujeito cognoscente individual, que aprende por experiências no trato com seu entorno natural, mas em situaçôes em que as mães remetem seus filhos a objetos a fim de ensinar-lhes alguma coisa" (p. 219). Portanto, a aquisição de Tomasello consiste na demonstraçáo de que crianças já em idade pré-linguística adquirem, por meio de gestos de indicaçấo e imitaçáo, a capacidade de estabelecer uma relação interpessoal em que se partilha uma perspectiva social sobre algo no mundo. "Para a filogênese, isso significa uma forma de trabalho conjunto e de aprendizado cooperativo nova e, em termos evolutivos, vantajosa, com a qual o saber comum pode ser simbolicamente acumulado e reflexivamente elaborado" (p. 220).

Esse capítulo importa para a democratizaçâo transnacional à medida que ressalta que os "três monopólios humanos" - a "produção de instrumentos", a "comunicaçáo simbólica" e a "normatização social de açóes" (p. 220) - são desenvolvidos mediante "uma linguagem cuja alta complexidade gramatical não pode ter caído do céu", mas foi estabelecida "partindo da solução de tarefas comunicativas universais que se colocam junto com a necessidade de coordenar de maneira conveniente as açōes dos diversos participantes" (p. 222). Portanto, a linguagem gramaticalmente diferenciada constitui a mediação do desenvolvimento cultural humano. A democratização transnacional também se apoia fundamentalmente nessa linguagem pragmaticamente desenvolvida, pois é apenas o uso comunicativo dela que possibilita a geração de um poder comunicativo que domestique os sistemas econômico e político mundiais.

No capítulo 12 ("'Como foi possível chegar a isso?' Uma resposta de Jan Philipp Reemtsma”), Habermas retoma a questão sobre como Auschwitz foi possível, questão sobre a qual Habermas destaca três observaçôes do intelectual político Reemtsma. Primeiro: "Que a Alemanha do pós-guerra foi erigida sobre um matadouro e que a maioria dos algozes se aposentou nele é um fato que emocionalmente jamais pode ser compreendido" (p. 229). Segundo: a explicação histórica do horror não pode ser mera apresentação objetivadora, mas tem de ser permeada pelo questionamento moral acerca da motivação e da responsabilidade dos algozes. Terceiro: a explicaçáo histórica do horror náo deve perder de vista o fato de que os algozes poderiam ter dito "não".

Esse capítulo é relevante para a democratização transnacional porque deixa claro que as atrocidades morais perpetradas pela humanidade não devem ser esquecidas; não devem ser normalizadas através da explicação normativamente vazia do ponto de vista do observador náo envolvido e incapaz de elaborar a significação prática de acontecimentos reificados; mas devem ser moralmente visíveis, expostas à crítica moral. A democratização transnacional depende da discussão crítica, ou seja, normativamente orientada à emancipação de toda pessoa, acerca das atrocidades morais historicamente marcantes que poderiam ter sido evitadas, mas não foram.

No capítulo 13 ("Kenichi Mishima no discurso intercultural"), Habermas, por ocasiáo da concessão do título de doutor honoris causa pela Freie Universität Berlin ao filósofo social Kenichi Mishima, admite, na esteira de Mishima, a existência de diversas modernidades. Para tanto, Habermas assume: que "ninguém pode sair de sua pele cultural” (p. 232), embora possa vestir-se com outras peles culturais no diálogo intercultural; que os processos de modernização não são meramente materiais, mas também fluem por canais culturais; que não faz sentido "a fixação [eurocêntrica] com a modernidade ocidental” (p. 233); que a teoria da 
sociedade deve ser "sensível à diversidade cultural dos processos de modernização", mas deve evitar "insuflar as tradições culturais formando totalidades fechadas" (p. 234). Baseado nessas premissas, Habermas conclui que "uma apropriação consciente da modernidade social a partir dos próprios recursos culturais faz surgir muitas modernidades, se as coisas vão bem" (p. 234).

A existência de múltiplas modernidades - e é isto que desponta, nesse capítulo, como indispensável à democratização transnacional - é uma idealização normativa cuja efetivação depende de uma política mundial não danificada por patologias (neo) colonialistas: "só podemos escapar realmente da sombra do colonialismo quando se exerce uma compreensão recíproca para a outra modernidade e para o pano de fundo cultural não familiar” (p. 236).

No capítulo 14 ("Da distância próxima. Um agradecimento à cidade de Munique"), Habermas aproveita a ocasiáo em que recebe o Prêmio de Honra Cultural da Cidade de Munique para ressaltar a falsa solidariedade (e a lucrativa austeridade) dos governos dos Estados ricos para com os cidadãos empobrecidos dos Estados economicamente arruinados. Ressalta também o imobilismo cívico em relação ao penar econômico de Estados estrangeiros: "Não somos gratos ao governo, que recolhe nosso dinheiro, também por ele ajudar a recalcar em nós o tema penoso de uma solidariedade impreterível, mas abandonada, para com os países do Sul?” (p. 241).

\section{5}

O coração do livro é formado pelas seçóes II e III pois elas tematizam direta e enfaticamente a idealização de uma democracia transnacional.

O capítulo 4 ("Palavras-chave para uma teoria discursiva do direito e do estado democrático de direito"), o qual abre a seção II, liga a obra principal de Habermas sobre direito e democracia - Facticidade e validade (1992) - com seu projeto teórico de uma democracia transnacional, esquematizado no ensaio Sobre a constituição da Europa (2011).

Habermas coloca do lado de cá da ponte, ou seja, na conta de Facticidade e validade: 1) a inadequação de "uma imagem institucionalmente congelada do estado democrático de direito" perante a "fluidificação comunicativa da política" (p. 98) em esferas públicas políticas vitalizadas; 2) a legitimação procedimental do direito positivo mediante o "vínculo de inclusão e deliberação" (p. 100) - a legalidade ganha legitimidade à medida que é criada pelos próprios concernidos ou por seus representantes (todos eles em igualdade de direitos e oportunidades) de modo argumentativo; 3) a cooriginariedade de direitos fundamentais constitucionalmente reconhecidos, de um lado, e soberania popular deliberativamente exercitada, de outro; (4) o paradigma jurídico do procedimentalismo democrático, o qual cose "laços de reacoplamento entre o processo democrático, que gera direitos e pretensôes subjetivas no interesse do cidadão da sociedade, e a asseguração de uma autonomia privada que, por seu turno, é indispensável para tornar possível um uso ativo da autonomia pública do cidadão do Estado" (pp. 102-103).

Do lado de lá da ponte, ou seja, na conta de Sobre a constituição da Europa, Habermas coloca: 1) a juridificação das relações internacionais desde a Segunda Guerra Mundial e a incipiente constitucionalização do direito internacional; 2) a premissa kantiana de que "um Estado mundial monopolizador da violência não é possível nem desejável" (p. 106); 3 ) "um conceito flexibilizado de direito" (p. 108) com base no qual a validade jurídica do direito internacional não seja enfraquecida ou até negada por faltar-lhe coerção e sobrar-lhe brandura; 4) "uma racionalização da substância violenta do poder estatal" (p. 109) à medida que, nas arenas internacionais, os Estados nacionais não se reduzem a competidores autocentrados que podem até injustamente guerrear para lograr objetivos unilaterais; 5) a crítica ao fato de que o direito internacional e as instituições internacionais, até agora, ganharam em eficiência organizatória, mas não em inclusão deliberativa dos cidadãos mundiais, sofrendo de um deficit democrático que não pode ser suprido pela observância de normas de direitos humanos, mas só pela democratização transnacional; 6) a crítica à emergência de uma governança transnacional tecnocrática; 7) a necessidade de, no curso da democratização transnacional, assegurar a 
existência dos Estados nacionais, tanto para manter por meio deles o nível de autonomia que os cidadãos nacionais já conquistaram como para que as normas transnacionais sejam apuradas quanto a sua conformidade às constituiçóes nacionais e executadas coercitivamente por eles (Estados nacionais), já que aparelhos administrativos coercitivos mundiais não deveriam ser criados.

O capítulo 5 ("Na esteira da tecnocracia. Um discurso em prol da solidariedade europeia") é o cerne do livro. Seu argumento principal é de que a União Europeia amarga uma deflação democrática e uma inflação tecnocrática: um "abismo entre politics [a discussão política nacionalmente acuada] e policies [as medidas políticas supranacionalmente engendradas e impostas]" (p. 120). Habermas detecta nas elites políticas europeias um apoio pragmático ao aprofundamento da união monetária em uma união política que ampliasse o controle coordenado de crises, assimetrias e disputas econômicas. Todavia, ele também detecta naquelas elites a preferência por conduzir essa união com cordéis tecnocráticos, sem crivo democrático. Por isso, Habermas alerta criticamente que faltam a uma uniāo tecnocrática "tanto o poder quanto o motivo para considerar suficientemente as demandas da população eleitora por justiça social, por segurança de status, por serviços públicos e bens coletivos, no caso de conflito com as injunçóes sistêmicas ligadas à capacidade de concorrência e ao crescimento econômico" (p. 129). Em última análise, a tecnocracia supranacional equivale à cristalização política de imperativos elitistas de autovalorização capitalista à revelia dos cidadãos nacionais.

Para a democratização da Uniāo Europeia, Habermas aponta três encaminhamentos políticos como importantíssimos: 1) uma união política tem de ser mais porosa que uma união monetária; 2) “a noção de que os Estados nacionais são 'os senhores dos tratados' tem de ser abandonada” (p. 131); 3) é necessário "passar do intergovernamentalismo para o "método comunitário"” (p. 132) - dos acordos negociados entre cúpulas executivas nacionais para leis criadas pelo Parlamento Europeu. Além disso, Habermas anota a necessidade de solidariedade política entre os Estados membros da Uniāo Europeia: "a ação solidária é necessária para ampliar as formas de integração sobrecarregadas de uma ordem política atropelada, isto é, adaptá-las às interdependências de longo alcance, produzidas sistemicamente, que se fazem notar aos próprios cidadãos só indiretamente, como restrição de sua autodeterminação política” (pp. 144-145). Portanto, Habermas sustenta que a solidariedade política, a ser equitativamente configurada em políticas europeias de redistribuição econômica, é condição incontornável da domesticação democrática de distúrbios graves, disparidades profundas e concorrências destrutivas na economia que ultrapassam as capacidades nacionais de controle administrativo.

\section{6}

O capítulo 6 ("O próximo passo. Uma entrevista”), o qual abre a seção III, reproduz uma entrevista de Habermas em que ele destaca o triunfo neoliberal em escala global e o atrofiamento das capacidades de controle político, mas recusa "o derrotismo cínico dos chamados realistas, que não concebem que os diagnósticos mais sombrios não nos desoneram de buscar o melhor" (p. 156). Em vez disso, ele perfilha "uma consciência de crise que não paralisa, mas é criativa” (p. 159). Trata-se, na esteira da crise de 2008, da "consciência para a necessidade de enfrentar as ameaças extorsivas dos mercados financeiros e dos riscos dos bancos, munindo-se de uma capacidade de ação política que se estenda para além do Estado nacional” (p. 163). Para Habermas, a situação presente torna indispensável "restabelecer um equilíbrio mais ou menos tolerável entre política e mercado" (p. 164), o que não pode mais ser alcançado no âmbito da política nacional,mas só mediante a democratização transnacional.

O capítulo 7 ("O dilema dos partidos políticos”) destaca o hiato entre política deliberativa democrática e políticas tecnocráticas elitistas na União Europeia: "os governos esperam poder acenar despercebidamente para regulamentaçóes econômicas inadiáveis no plano da policy, sem alterar as instituições políticas” (p. 168), mantendo o papel dos executivos nacionais sob os holofotes e o papel do Parlamento Europeu sob as sombras. Assim, Habermas alerta para o fato de que a União 
Europeia se encontra "no caminho pós-democrático de um federalismo executivo que age em conformidade com o mercado, isto é, talhado para os imperativos do mercado financeiro" (p. 171). Com isso, não só a democracia é fraudada no plano europeu, mas também o mercado financeiro permanece desregulado e afetando inevitavelmente os Estados e os cidadãos nacionais. Nesse cenário, Habermas destaca que os partidos políticos assumem uma tarefa democratizante que lhes requer não se confinar aos objetivos prudenciais de conquista e conservação do poder político no plano nacional, mas lhes requer orientação emancipatória, coragem cívica e liderança pragmática no sentido de consolidar a soberania popular para além dos casulos nacionais.

No capítulo 8 ("Três razóes para mais Europa”), Habermas oferece uma justificação da desejabilidade de um apoio alemão à democratização europeia. Traduzo essa justificação local nas seguintes razóes universais para uma democracia transnacional: 1) expulsar o espectro de um nacionalismo ensimesmado, tendencialmente belicista; 2) reverter a tendência neoliberal, em cujo rastro "a política se submete aos imperativos do mercado, e se acata o aumento de desigualdade", de modo que "os mecanismos sistêmicos escapam cada vez mais à influência intencional do direito democraticamente positivado" (p. 177); 3) a domesticação da economia capitalista transnacionalmente impactante só pode ser legítima se realizada democraticamente, mediante a criação de um parlamento mundial.

No capítulo 9 ("Democracia ou capitalismo? Da miséria de uma sociedade mundial fragmentada pelos Estados nacionais e integrada pelo capitalismo"), Habermas polemiza com o sociólogo Wolfgang Streeck quanto à guinada neoliberal dos anos de 1970 - "golpe libertador dos proprietários de capital e de seus executivos em relação a um estado democrático que apertava as margens de lucro das empresas em favor da justiça social, mas que, do ponto de vista dos investidores, estrangulava o crescimento econômico, prejudicando, com isso, o suposto interesse geral" (pp. 184-185). O ponto nodal da polêmica é: qual caminho deve ser trilhado para resgatar a soberania popular do império de bancos privados e investidores sagazes? Habermas e Streeck concordam quanto ao diagnóstico críti- co do "desacoplamento das esferas públicas e dos parlamentos nacionais em relação ao concerto de governos submissos ao mercado, desprendido e tecnocraticamente autonomizado" (p. 186). A divergência entre eles é sobre como revitalizar a democracia. Enquanto para Habermas é necessário transnacionalizar a democracia, Streeck acredita que é necessário recuperar domesticamente as capacidades do Estado nacional. Segundo Habermas, Streeck não consegue dar conta dos potenciais normativos de mudança política de uma sociedade mundial que está "em fusão sistêmica, mas, hoje como ontem, politicamente anárquica” (p. 188). Ele também não ilumina normativamente o horizonte político para além da constelação presente de cooperação nula entre Estados nacionais impotentes, a qual é resultado da "fragmentação política de uma sociedade mundial que é, contudo, integrada economicamente" (p. 189). De acordo com Habermas, só o desenvolvimento de instituições políticas democráticas mundiais pode restabelecer o equilíbrio entre a autonomia pública dos cidadáos mundiais, de um lado, e a autonomia privada de atores econômicos, de outro.

Em última análise, Habermas, apesar de sua diversidade temática e das múltiplas referências às políticas europeia e alemá, mira a subpolítica transnacional em NET. Trata-se de uma obra sobre a presente constelação política pós-nacional, caracterizada: primeiro, como extremamente carente de uma democratização enfática que se expresse em regulações e instituiçóes políticas supranacionais; segundo, como irredutível a fronteiras nacionais, uma vez que é composta de problemas práticos (morais, éticos e pragmáticos) e interdependências sociais (produtivas, distributivas, organizatórias e decisórias) que cruzam territórios nacionais e regionais e apenas podem ser levados a sério e resolvidos mediante deliberaçóes universalmente includentes e decisóes universalmente vinculantes. Em especial, as crises econômicas engendradas pelo destrutivo funcionamento do capitalismo neoliberal globalizado e os encaminhamentos tecnocráticos da política 
transnacional, a qual se encontra rendida às negociaçóes, às barganhas, à sagacidade e ao autointeresse de cúpulas políticas e grandes empresas nacionais, clamam pela democratização transnacional.

\section{BIBLIOGRAFIA}

HABERMAS, Jürgen. ([1992] 2003), Direito e democracia: entre facticidade e validade. Trad. Flávio Beno Siebeneichler. Rio de Janeiro, Tempo Brasileiro.

HABERMAS, Jürgen (2011). Sobre a constituição da Europa.Trad. Denilson Luís Werle, Luiz Repa e Rúrion Melo. São Paulo, Unesp.

WALDRON, Jeremy. (2015), "The vanishing Europe of Jürgen Habermas". The New York Review of Books, 62 (16). Disponível em www.nybooks.com/articles/2015/10/22/vanishing-europe-jurgen-habermas, consultado em $6 / 8 / 2017$. 